\title{
Pengaruh Perbedaan Jenis Medium Perendaman Terhadap Vase Life Bunga Potong Mawar Merah
}

\author{
Adila Hafidzani Nur Fitria, Dinda Widyani, Elis Kurniani, Jihan Nurhalimah Salsabila, Kelvin \\ Pramudya Anantatur, Meli Driyani, Nabila Tazkiyyatul Afifah, Narti Nurhatifah, Neng lis Nur \\ Istiqomah, Rudhya Nurul Ilma, Suti Supadmi, Syafira Aulia Putri, Syifa Marwah, Taufik Rahman, \\ Tri Suwandi* \\ Departemen Pendidikan Biologi, Fakultas Pendidikan Matematika dan Ilmu Pengetahuan Alam \\ Universitas Pendidikan Indonesia \\ *E-mail: trisuwandi@upi.edu
}

\begin{abstract}
Abstrak
Bunga mawar (Rosa hybrida) merupakan salah satu jenis bunga potong yang memiliki nilai ekonomi tinggi dan sangat prospektif untuk dikembangkan secara komersial. Namun, kesegaran dari bunga mawar merah potong tidak mampu bertahan lama akibat kandungan air yang tinggi pada mawar. Salah satu upaya untuk mempertahankan kualitas dan memperpanjang masa kesegaran bunga adalah dengan pemberian larutan perendam. Umumnya larutan perendam terdiri dari air, gula (sukrosa), bakterisida, dan antibiotik. Penelitian ini bertujuan untuk mengetahui pengaruh jenis medium terhadap vase life bunga potong mawar merah dan jenis medium yang paling efektif untuk memperpanjang vase life bunga potong mawar merah. Penelitian dilaksanakan dengan 6 perlakuan dan 3 kali ulangan. Perlakuan yang diuji, yaitu A (air mineral), AG (Air dan larutan gula 1\%), GK1 (larutan gula 1\% dan ekstrak kemangi 12,5\%), GK2 (larutan gula 1\% dan ekstrak kemangi 25\%), GB1 (larutan gula 1\% dan ekstrak belimbing wuluh $12,5 \%$ ), GB2 (larutan gula 1\% dan ekstrak belimbing wuluh 25\%). Dan dalam setiap perlakuan berisi tiga bunga mawar potong. Data diolah secara statistik dengan teknik pengolahan data menggunakan Uji ANOVA dan uji Duncan. Hasil penelitian menunjukkan bahwa perlakuan A, AG dan GB1 menunjukan tingkat kesegaran bunga yang paling tinggi, sedangkan pada perlakuan GK2 menunjukan tingkat kesegaran bunga yang paling rendah.
\end{abstract}

Kata kunci: Bunga mawar, vase life, medium perendaman.

\begin{abstract}
Rose (Rosa hybrida) is a type of cut flower that has high economic value and is very prospective for commercial development. However, the freshness of cut red roses cannot last long due to the high water content in roses. One of the efforts to maintain the quality and extend the freshness period of the flowers is by giving a soaking solution. Generally, the soaking solution consists of water, sugar (sucrose), bactericide, and antibiotics. This study aims to determine the effect of the type of medium on the vase life of cut flowers of red roses and the type of medium that is most effective in extending the vase life of cut flowers of red roses. The research was carried out with 6 treatments and 3 replications. The treatments tested were A (mineral water), AG (Water and $1 \%$ sugar solution), GK1 (1\% sugar solution and $12.5 \%$ basil extract), GK2 (1\% sugar solution and $25 \%$ basil extract), GB1 (1\% sugar solution and $12.5 \%$ starfruit extract), GB2 ( $1 \%$ sugar solution and $25 \%$ starfruit extract). And in each treatment contains three cut roses. The data were processed statistically with data processing techniques using the ANOVA test and Duncan's test. The results showed that treatment A, AG and GB1 showed the highest flower freshness level, while the GK2 treatment showed the lowest flower freshness level.
\end{abstract}

Keywords : Rose flower, vase life, soaking mediu

http://ejournal.urindo.ac.id/index.php/pertanian

Article History :

Sumbitted 03 Juni 2021, Accepted 30 Juni2021, Published 30 Juni2021 


\section{PENDAHULUAN}

Mawar (Rosa hybrida) atau biasa disebut bunga ros merupakan salah satu jenis bunga potong unggulan nasional yang populer di Indonesia. Mawar memiliki nilai ekonomi tinggi dan sangat prospektif untuk dikembangkan secara komersial. Mawar potong banyak diminati para dekorator, florist, hotel, restoran, maupun pengguna mawar untuk penghias interior rumah. Mawar telah menjadi bagian dari kehidupan masyarakat Indonesia dan banyak ditampilkan masyarakat pada berbagai event, seperti acara kelahiran, upacara keagamaan, ulang tahun kemerdekaan dan acara pesta perkawinan. Daya tarik bunga mawar potong, antara lain disebabkan karena keindahan bentuk dan warnanya yang sangat bervariasi dengan harga relatif terjangkau dan relatif stabil. Mawar bisa ditanam setiap saat, disesuaikan kebutuhan pasar dengan masa produksi sekitar tiga tahun dengan nilai keuntungan cukup tinggi. Hal demikian yang menyebabkan penggunaan mawar potong dalam rangkaian bunga maupun dekorasi cukup tinggi dan banyak berdampak pada banyaknya jumlah petani yang menekuni usaha produksi mawar [10].

$$
\text { Kesegaran bunga merupakan }
$$
komponen utama yang dapat digunakan sebagai penentu kualitas dari bunga potong. Masa kesegaran dihitung mulai bunga dipanen hingga menjadi layu [17]. Namun, kesegaran dari bunga mawar merah potong tidak mampu bertahan lama. Lambat-laun bunga akan layu dan kelopaknya pun ikut berguguran sehingga tidak seindah dalam keadaan segar. Hal ini menjadi permasalahan yang sering terjadi pada bunga potong mawar merah, yaitu kesegaran bunga yang hanya empat sampai lima hari saja akibat kandungan air yang tinggi pada mawar. Sehingga menjadi kendala utama yang sering dihadapi oleh petani karena produk hasil pertaniannya memiliki umur simpan yang pendek. Bunga potong yang dipasarkan harus mempunyai kualitas yang baik diantaranya mempunyai masa kesegaran yang cukup panjang. Sifat tersebut sangat dipengaruhi oleh penanganan pasca panen. Salah satu upaya untuk mempertahankan kualitas dan memperpanjang masa kesegaran bunga adalah dengan pemberian larutan perendam. Umumnya larutan perendam terdiri dari air, gula (sukrosa), bakterisida, dan antibiotik $[7,8,13]$.

Perendaman larutan nutrisi dan pemberian pengawet merupakan salah satu teknologi yang dapat dengan mudah diterapkan pada bunga potong. Larutan tersebut dapat dibuat melalui kombinasi bahan yang mengandung karbohidrat sebagai sumber energi dan asam sitrat sebagai penurun $\mathrm{pH}$ larutan ataupun pengawet [2]. Menurut Riyanto (2012), penggunaan gula pasir pada bunga potong adalah sebagai substrat respirasi dan pengatur osmosis dalam menjaga keseimbangan air. Pengawet yang digunakan dalam larutan perendaman tidak harus selalu berupa pengawet kimia, namun 
bisa berupa pengawet alami. Ismawati (2013) menyatakan bahwa dalam 100 gram belimbing wuluh mengandung asam organik yang salah satunya terdiri dari asam sitrat. Selain itu, bahan alami lainnya yang dapat digunakan sebagai pengganti pengawet kimia adalah ekstrak daun kemangi (Ocimum americanum L.). Menurut Arisanti (2013) ekstrak daun kemangi mengandung senyawa flavonoid yang dapat digunakan sebagai antioksidan alami pada larutan perendam bunga potong.

Perendaman bunga potong menggunakan larutan perendaman telah banyak diteliti sebelumnya. Laksono (2020), melakukan perendaman bunga potong krisan menggunakan kombinasi gula pasir dan sari belimbing wuluh. Pemberian larutan perendaman berupa kombinasi sari belimbing wuluh $2 \%$ dengan gula $1 \%$ menunjukan hasil terbaik dalam mempertahankan umur kesegaran bunga potong krisan hingga 17,8 hari. Selain itu, Arisanti (2013) melakukan perendaman bunga potong krisan dengan kombinasi hidrogel karagenan sebagai sumber energi dan ekstrak daun kemangi. Pada penelitian tersebut menunjukan bahwa pemberian $400 \mathrm{ml}$ ekstrak daun kemangi konsentrasi $250 \mathrm{~g} / \mathrm{l}$ dan gel karagenan $10 \mathrm{~g}$ dapat memperpanjang masa kesegaran bunga potong krisan selama 12,67 hari $[4,7]$.

Atas landasan tersebut, dilakukan penelitian menggunakan beberapa bahan yang mudah didapatkan di sekitar, seperti ekstrak kemangi, sari belimbing wuluh, dan gula sebagai bahan larutan perendaman bunga potong mawar. Ekstrak kemangi mengandung senyawa flavonoid sebagai antioksidan, mengandung komponen non gizi, serta mampu menghambat pertumbuhan bakteri, karena mengandung senyawa saponin, flavonoid, dan tanin pada daunnya $[5,6]$. Sari belimbing wuluh diketahui mengandung asam sitrat yang tinggi dan berperan sebagai pengawet alami dalam larutan perendaman. Selain itu, gula merupakan bagian penting dalam larutan perendaman yakni sebagai sumber energi atau merupakan substrat respirasi dan pengatur osmosis dalam menjaga keseimbangan air [4, $6,7]$.

Tujuan dari penelitian ini adalah untuk mengetahui pengaruh jenis medium terhadap vase life bunga potong mawar merah dan jenis medium yang paling efektif untuk memperpanjang vase life bunga potong mawar merah.

\section{METODE}

\subsection{Metode Penelitian dan Pendekatan}

Penelitian dilakukan melalui penelitian kuantitatif dengan pendekatan eksperimental.

\subsection{Waktu dan Tempat}

Penelitian dilaksanakan selama 10 hari yakni dimulai pada hari Selasa, 13 April 2021 sampai Jum'at, 23 April 2021. Penelitian ini dilakukan di Komplek Griya Bandung Indah Blok J3 No. 3A, Kab.Bandung.

\subsection{Alat dan Bahan}

Alat yang digunakan dalam penelitian 
ini adalah panci, kompor, blender, saringan, wadah larutan, gelas ukur, label, tabung gelas, dan wadah perendaman.

Bahan yang digunakan dalam penelitian ini adalah bunga mawar merah potong, $200 \mathrm{ml}$ larutan gula 1\%, $100 \mathrm{ml}$ Larutan gula $1 \%$ (larutan A), $100 \mathrm{ml}$ sari belimbing wuluh 12,5\%, $100 \mathrm{ml}$ sari belimbing wuluh 25\%, $100 \mathrm{ml}$ ekstrak daun kemangi $25 \%$.

\subsection{Prosedur Penelitian}

Penelitian dilaksanakan dengan 6 perlakuan dan 3 kali ulangan. Perlakuan yang diuji, yaitu perendaman bunga potong mawar merah pada larutan A (air mineral), larutan AG (larutan gula 1\%), larutan GK1 (larutan gula 1\% dan ekstrak kemangi 12,5\%), larutan GK2 (larutan gula 1\% dan ekstrak kemangi 25\%), larutan GB1 (larutan gula 1\% dan ekstrak belimbing wuluh 12,5\%), dan larutan GB2 (larutan gula 1\% dan ekstrak belimbing wuluh 25\%). Dalam setiap perlakuan berisi tiga bunga mawar potong. Pengamatan dilakukan selama 10 hari dengan interval waktu 2 hari sekali karena tidak menemukan perbedaan pada pengamatan setiap sehari sekali.

\section{Kelayuan Bunga (Senescence)} dilakukan dengan metode skoring. Perubahan penampilan fisik bunga sebagai penentuan skoring adalah sebagai berikut: (a) bunga mekar sempurna; (b) kuntum bunga tegak dengan mahkota segar, berwarna cerah; (c) tangkai bunga segar berwarna hijau; (d) ujung mahkota bunga lemas, mengering, menutup (keriput) atau menggulung ke dalam; (e) mahkota bunga terbuka lebih dari 900 terhadap garis vertikal; (f) terkulainya tangkai pada bagian dasar mahkota bunga hingga mahkota bunga merunduk; (g) tangkai berubah warna menjadi coklat; (h) terjadi perubahan warna menjadi lebih pucat atau memudarnya warna mahkota bunga.

Dengan ketentuan skoring Skor 1 = Segar (semua ciri a,b,c yang dideskripsikan dalam teks), Skor $\mathbf{2}$ = Mulai layu (salah satu atau kombinasi ciri d,e,f,g,h yang dideskripsikan dalam teks) dan Skor $\mathbf{3}=$ Layu (Senescence/mati semua ciri d,e,f,g,h) [1,12].

Langkah awal penelitian adalah menyiapkan alat dan bahan yang dibutuhkan. Bahan seperti larutan gula, ekstrak kemangi, dan sari belimbing wuluh dibuat terlebih dahulu. Kemudian setiap wadah diberi label $A, B, C, D, E, F$. Masing-masing wadah tersebut diisi oleh larutan sebanyak $200 \mathrm{ml}$ sesuai perlakuan. Selanjutnya masing-masing wadah tersebut diisi 3 bunga mawar potong. Kemudian diamati perubahan yang terjadi pada setiap wadah setiap harinya.

Parameter yang diamati yaitu penampilan fisik berupa kelayuan bunga (Senescence) dengan metode skoring. Pengamatan dilakukan selama 10 hari.

\subsection{Analisis data}

Data yang didapat dari hasil penelitian diolah secara statistik dengan teknik pengolahan data menggunakan Uji ANOVA karena data berdistribusi normal. Hasil uji ANOVA menunjukkan adanya perbedaan 
nyata. Maka, dilanjutkan dengan uji Duncan.

\section{HASIL DAN PEMBAHASAN}

Berdasarkan hasil penelitian tentang tingkat kesegaran bunga mawar potong yang direndam dalam air, larutan gula, campuran larutan gula dengan ekstrak belimbing wuluh, serta campuran larutan gula dengan ekstrak kemangi ditampilkan dalam tabel 1.

Tabel 1. Rekapitulasi Hasil Uji Duncan Terhadap skor vase life bunga potong mawar.

\begin{tabular}{|c|c|c|c|c|c|c|c|}
\hline \multirow{2}{*}{ Ulangan } & \multirow{2}{*}{$\begin{array}{c}\text { Media } \\
\text { Perendaman }\end{array}$} & \multicolumn{5}{|c|}{ Rata-rata skoring hari ke- } & \multirow{2}{*}{ Rata-rata } \\
\hline & & 2 & 4 & 6 & 8 & 10 & \\
\hline \multirow[t]{6}{*}{1} & A & $1.00^{\mathrm{abc}}$ & $1.00^{\mathrm{abc}}$ & $2,40^{\mathrm{abc}}$ & $2,60^{\mathrm{abc}}$ & $3.00^{\mathrm{abc}}$ & $2.00^{\mathrm{abc}}$ \\
\hline & AG & $1.00^{\mathrm{abc}}$ & $1.00^{\mathrm{abc}}$ & $2,60^{\mathrm{abc}}$ & $2,60^{\mathrm{abc}}$ & $3.00^{\mathrm{abc}}$ & $2,04^{\mathrm{abc}}$ \\
\hline & GK1 & $1.00^{\mathrm{ab}}$ & $2,20^{\mathrm{ab}}$ & $2,60^{a b}$ & $2,80^{\mathrm{ab}}$ & $3.00^{\mathrm{ab}}$ & $2,32^{\mathrm{ab}}$ \\
\hline & GK2 & $1.00^{\mathrm{a}}$ & $2,20^{\mathrm{a}}$ & $2,80^{a}$ & $2,80^{a}$ & $3.00^{\mathrm{a}}$ & $2,36^{a}$ \\
\hline & GB1 & $1.00^{\mathrm{abc}}$ & $1.00^{\mathrm{abc}}$ & $2,60^{\mathrm{abc}}$ & $2,60^{\mathrm{abc}}$ & $3.00^{\mathrm{abc}}$ & $2,04^{\mathrm{abc}}$ \\
\hline & GB2 & $1.00^{\mathrm{abc}}$ & $1.00^{\mathrm{abc}}$ & $2,60^{\mathrm{abc}}$ & $2,80^{\mathrm{abc}}$ & $3.00^{\mathrm{abc}}$ & $2,08^{\mathrm{abc}}$ \\
\hline \multirow[t]{6}{*}{2} & A & $1.00^{\mathrm{abc}}$ & $1.00^{\mathrm{abc}}$ & $2,60^{\mathrm{abc}}$ & $2,80^{\mathrm{abc}}$ & $3.00^{\mathrm{abc}}$ & $2,08^{\mathrm{abc}}$ \\
\hline & AG & $1.00^{\mathrm{abc}}$ & $1.00^{\mathrm{abc}}$ & $2,40^{\mathrm{abc}}$ & $2,60^{\mathrm{abc}}$ & $3.00^{\mathrm{abc}}$ & $2.00^{\mathrm{abc}}$ \\
\hline & GK1 & $1.00^{\mathrm{ab}}$ & $2,20^{\mathrm{ab}}$ & $2,60^{a b}$ & $2,80^{\mathrm{ab}}$ & $3.00^{\mathrm{ab}}$ & $2,32^{\mathrm{ab}}$ \\
\hline & GK2 & $1.00^{\mathrm{a}}$ & $2,20^{\mathrm{a}}$ & $2,80^{\mathrm{a}}$ & $2,80^{a}$ & $3.00^{\mathrm{a}}$ & $2,36^{a}$ \\
\hline & GB1 & $1.00^{\mathrm{abc}}$ & $1.00^{\mathrm{abc}}$ & $2,60^{\mathrm{abc}}$ & $2,60^{a b c}$ & $3.00^{\mathrm{abc}}$ & $2,04^{\mathrm{abc}}$ \\
\hline & GB2 & $1.00^{\mathrm{abc}}$ & $1.00^{\mathrm{abc}}$ & $2,60^{\mathrm{abc}}$ & $2,80^{\mathrm{abc}}$ & $3.00^{\mathrm{abc}}$ & $2,08^{\mathrm{abc}}$ \\
\hline \multirow[t]{6}{*}{3} & A & $1.00^{c}$ & $1.00^{c}$ & $2,20^{c}$ & $2,40^{c}$ & $2,80^{\mathrm{c}}$ & $1,88^{c}$ \\
\hline & AG & $1.00^{b c}$ & $1.00^{b c}$ & $2,40^{b c}$ & $2,60^{b c}$ & $2,80^{b c}$ & $1,96^{\mathrm{bc}}$ \\
\hline & GK1 & $1.00^{\mathrm{abc}}$ & $1.00^{\mathrm{abc}}$ & $2,60^{\mathrm{abc}}$ & $2,80^{\mathrm{abc}}$ & $3.00^{\mathrm{abc}}$ & $2,08^{\mathrm{abc}}$ \\
\hline & GK2 & $1.00^{\mathrm{ab}}$ & $2,20^{\mathrm{ab}}$ & $2,60^{a b}$ & $2,80^{\mathrm{ab}}$ & $3.00^{\mathrm{ab}}$ & $2,32^{\mathrm{ab}}$ \\
\hline & GB1 & $1.00^{c}$ & $1.00^{c}$ & $2,20^{c}$ & $2,40^{c}$ & $2,60^{c}$ & $1,84^{c}$ \\
\hline & GB2 & $1.00^{\mathrm{ab}}$ & $2,20^{\mathrm{ab}}$ & $2,60^{\mathrm{ab}}$ & $2,80^{\mathrm{ab}}$ & $3.00^{\mathrm{ab}}$ & $2,32^{\mathrm{ab}}$ \\
\hline
\end{tabular}

Keterangan: Angka-angka yang diikuti huruf yang sama pada baris dan kolom yang sama, berarti tidak berbeda nyata menurut uji Duncan pada taraf $5 \%$. 
Tabel 2. Dokumentasi Perendaman Bunga Mawar Potong pada Hari Ke-8.

\begin{tabular}{|c|c|c|c|c|c|}
\hline A & AG & GK1 & GK2 & GB1 & GB2 \\
\hline $\begin{array}{c}\text { Gambar 1. } \\
\text { Hari ke - 8 } \\
\text { Perendaman } \\
\text { dengan } \\
\text { larutan A }\end{array}$ & $\begin{array}{c}\text { Gambar 2. } \\
\text { Hari ke - 8 } \\
\text { dendaman } \\
\text { larutan AG }\end{array}$ & $\begin{array}{c}\text { Gambar 3. } \\
\text { Hari ke - 8 } \\
\text { Perendaman } \\
\text { dengan } \\
\text { larutan GK1 }\end{array}$ & $\begin{array}{c}\text { Gambar 4. Hari } \\
\text { ke - 8 } \\
\text { Pengan laman } \\
\text { dengatan } \\
\text { GK2 }\end{array}$ & $\begin{array}{c}\text { Gambar 5. } \\
\text { Hari ke - 8 } \\
\text { Perendaman } \\
\text { dengan } \\
\text { larutan GB1 }\end{array}$ & $\begin{array}{c}\text { Gambar 6. } \\
\text { Hari ke - 8 } \\
\text { Pendaman } \\
\text { dengan } \\
\text { larutan GB2 }\end{array}$ \\
\hline
\end{tabular}

Keterangan: A (Air mineral), AG ( Air + Air gula 1\%), GK1 (Air gula 1\% + Ekstrak kemangi 12,5\%), GK2 (Air gula $1 \%+$ Ekstrak kemangi 25\%), GB1 (Air gula 1\% + Ekstrak belimbing wuluh 12,5\%), GB2 (Air gula 1\% + Ekstrak belimbing wuluh 25\%).

Pada tabel 1 menunjukkan bahwa perlakuan $A G$ dan GB1 menunjukkan hasil yang dapat memperlambat kelayuan, terlihat dengan keadaan bunga pada tabel 2 yang tidak sepenuhnya layu karena hanya memiliki salah satu atau kombinasi ciri d,e,f,g,h. Penggunaan gula pasir pada bunga potong adalah sebagai substrat respirasi dan pengatur osmosis dalam menjaga keseimbangan air dan gula merupakan karbohidrat sederhana yang larut dalam air dan mudah diserap untuk diubah menjadi energi [14]. Sementara, buah belimbing wuluh (Averrhoa blimbi Linn.) dapat dimanfaatkan sebagai pengawet alami. Aplikasi perendaman dengan sari belimbing wuluh karena kandungan asam sitrat yang tinggi. Asam sitrat yang diaplikasikan pada bunga potong dapat menurunkan $\mathrm{pH}$, meningkatkan keseimbangan air, dan mengurangi penyumbatan pada batang, sehingga kelayuan dapat ditunda [11]. Selain itu, belimbing wuluh juga memiliki banyak sekali kandungan senyawa antara lain saponin, flavonoid dan polifenol. Flavonoid merupakan senyawa fenol yang dapat menyebabkan denaturasi protein dan berfungsi sebagai antibakteri dan antijamur [3].

Berdasarkan perhitungan rerata kelayuan bunga mawar potong pada berbagai perlakuan media perendaman, perlakuan $A$, AG dan GB1 memiliki rata-rata terendah sebesar 1,98. Hal ini menunjukan tingkat kesegaran bunga yang paling tinggi dikarenakan larutan perendamannya mengandung gula dan belimbing wuluh yang dapat meningkatkan kesegaran bunga. Secara data, tampak A yang merupakan kontrol, AG, dan GB1 tidak berbeda secara nyata. Namun pada saat percobaan terlihat bahwa $A$ atau kontrol memberikan hasil bunga yang lebih 
lemas dan layu dibandingkan bunga mawar yang diberi perlakuan AG dan GB1.

Pada perlakuan GK2 memiliki rata-rata tertinggi sebesar 2,33. Hal ini menunjukan tingkat kesegaran bunga yang paling rendah terlihat dengan keadaan bunga yang memiliki semua ciri d,e,f,g,h. Walaupun Ekstrak daun kemangi mengandung senyawa flavonoid sebagai antioksidan alami pada larutan perendam bunga potong yang mampu menjadi bahan pengawet, tetapi pada percobaan yang kami lakukan menunjukan hal yang bertentangan. Berdasarkan hasil percobaan, kesegaran bunga tidak dapat dipertahankan lebih lama dibandingkan hasil perlakuan lain, hal ini diduga akibat perbedaan jenis bunga. Berdasarkan percobaan yang dilakukan oleh Arisanti et al. (2013) menunjukan bahwa media perendaman dengan ekstrak daun kemangi pada bunga Krisan Putih memberikan hasil yang baik, sedangkan pada percobaan kami yang menggunakan bunga mawar menunjukan hasil percobaan yang kurang baik [4].

\section{KESIMPULAN}

Berdasarkan hasil percobaan yang dilakukan, dapat disimpulkan bahwa perlakuan pemberian medium dengan konsentrasi berbeda berpengaruh terhadap vase life bunga potong mawar merah. Jenis medium yang paling efektif untuk memperpanjang vase life bunga potong mawar merah adalah air gula konsentrasi $1 \%$ dan campuran air gula konsentrasi $1 \%$ dengan ekstrak belimbing wuluh konsentrasi $12,5 \%$.

Untuk dapat mempertahankan vase life bunga mawar potong disarankan mengkaji literatur lebih banyak dan melakukan penelitian lebih lanjut dengan konsentrasi larutan yang bervariasi untuk mengetahui konsentrasi medium yang optimal untuk memperpanjang vase life bunga potong dan pengaruh ekstrak daun kemangi terhadap vase life bunga potong mawar merah dan krisan putih.

\section{DAFTAR PUSTAKA}

Ahyana BN, Haeri PS, DA CR. Efek Gula terhadap Kesegaran Bunga Potong Chrysanthemum sp. Studi Empiris. Universitas Mataram. 2015.

Amiarsi, D., R. Tejasrwana. Pengawet untuk Menjaga Kualitas Bunga Potong Mawar Selama Penyimpanan. J.Hort. 2011 Juni 6;21(3):274-279.

Ardananurdin A, Winarsih S, Widayat M. Uji Efektifitas Dekok Bunga Belimbing Wuluh (Averrhoa bilimbi) sebagai antimikroba terhadap bakteri Salmonella Typhi secara in vitro. Jurnal Kedokteran Brawijaya. 2013 Apr 9;20(1):30-4.

Arisanti D, Prihastanti E, Kusdiyantini E. Pengaruh Komposisi Medium Perendam terhadap Masa Kesegaran Bunga Potong Krisan (Chrysanthemum morifolium R.). Jurnal Akademika Biologi. 2013 Nov 
$14 ; 2(4): 35-44$.

Deviyanti PN, Dewi EN, Anggo AD. Efektivitas

Daun Kemangi (Ocimum Sanctum L.) Sebagai Antibakteri Pada Ikan Kembung Lelaki (Rastrelliger Kanagurta) Selama Penyimpanan Dingin. Jurnal Pengolahan dan Bioteknologi Hasil Perikanan. 2015 Aug 29;4(3):1-6.

Hamiyanti AA, Sutomo B, Rozi AF, Adnyono Y, Darajat R. Pengaruh penambahan tepung kemangi (Ocimum basilicum) terhadap komposisi kimia dan kualitas fisik ayam broiler. Jurnal IImu-IImu Peternakan. 2013 Oct $24 ; 23(1): 25-9$.

Laksono AD, Widyawati N. Pengaruh Larutan Perendaman Sari Belimbing Wuluh Dan Gula Terhadap Vase Life Bunga Potong Krisan Standar Putih (Dendranthema grandiflora L.) 'White Fiji'. Jurnal Teknik Pertanian Lampung (Journal of Agricultural Engineering). 2020 Mar $31 ; 9(1): 10-8$.

Putra DM, Yuswanti H, Darmawati IA. Penggunaan Chrysal untuk Memperpanjang Kesegaran Bunga Potong Mawar (Rosa hybrida L.). Jurnal Agroekoteknologi Tropika (Journal of Tropical Agroecotechnology):322-31.

Sumiati S, Marjanah M. Perbandingan Buah Belimbing Wuluh (Averrhoa Bilimbi) dan Daun Kemangi (Ocimum Sanctum) sebagai Bahan Pengawet Alami Ikan Kembung (Rastrellinger sp.). Jurnal Jeumpa. 2020
Dec 11;7(2):422-32.

Tarigan, H., K. Profil Agribisnis Mawar di Indonesia. Direktorat Jenderal Holtikultura Kementerian Pertanian. 2018 [26 Mei 2021] Di akses dari: http://hortikultura.pertanian.go.id/wpcontent/uploads/2018/11/Tulisan-IImiah-

\section{Oktober.pdf}

Veronika, R. Memperpanjang Umur Simpan Bunga Krisan Potong Tipe Yellow Fiji dengan Perlakuan Pra Penyimpanan, Suhu, dan Komposisi Larutan Pulsing untuk Mempertahankan Kesegaran Selama Penyimpanan. Bogor : Repository IPB. 2008.

Wiraatmaja IW, Astawa IN, Devianitri NN. Memperpanjang Kesegaran Bunga Potong Krisan (Dendranthema grandiflora Tzvelev.) dengan Larutan Perendam Sukrosa dan Asam Sitrat. Jurnal Agritrop. 2007;26(3):129-35.

Zagory D, Reid MS. Evaluation of the role of vase microorganisms in the postharvest life of cut flowers. InIII International Symposium on Postharvest Physiology of Ornamentals 1811985 Jul 1 (pp. 207-218).

Darwin, P. Menikmati Gula Tanpa Rasa

Takut, Sinar Ilmu, Yogyakarta, 2013.

Riyanto. Pengawetan Bunga Potong Sedap Malam dengan Larutan Perak Nitrat. Jurnal Agrisains. 2012: 46-53.

Ismawati. Ekstrak Air Buah Belimbing Wuluh 
Jurnal IImiah Respati

(Averrhoa bilimbi L.) sebagai Reduktor dalam Pembuatan Nanomagnetik.

[Skripsi]. Institut Pertanian Bogor. 2013.

Ariyanto $R$, Mulyaningrum ER, Rahayu $P$.

Pengaruh Ekstrak Jeruk Nipis dengan

Larutan Gula Kelapa terhadap

Keterserapan Larutan dan Lama

Kesegaran pada Bunga Potong Krisan. J.

Biologi dan Pembelajarannya. 2018

Oct;5(2):32-7. 